\title{
Acoustic-Emission Characteristics of Uniaxial-Compression Process in Modified Polyester Fiber-Reinforced Concrete
}

\author{
Yu Gao ${ }^{1,2^{*}}$, Hongguang Ji1 ${ }^{2}$, Jianqiang Chen $^{3}$ and Chunhui $\mathrm{Zhao}^{4}$ \\ ${ }^{1}$ School of Civil and Resource Engineering, University of Science and Technology Beijing, Beijing 100083, China \\ ${ }^{2}$ Beijing Key Laboratory of Urban Underground Space Engineering, University of Science and Technology Beijing, Beijing 100083, \\ China \\ ${ }^{3}$ School of Civil Engineering, Qingdao University of Technology, Qingdao 266033, China \\ ${ }^{4}$ YU\&Associates, inc, 200 Riverfront Blvd, Elmwood Park, NJ 07407, USA
}

Received 20 June 2021; Accepted 20 August 2021

\begin{abstract}
In order to reveal the influence of the different amounts of admixture of MPF on the mechanical properties of concrete and the mechanism of fiber inhibiting the damage process, a uniaxial-compression test based on acoustic emission (AE) technology is proposed in this study. Based on the proposed test, the changes in AE ringing count, $r$ value, RA-AF distribution, and main frequency characteristics of C30 concrete cube specimens with different fiber contents were obtained. Combined with the stress-strain relationship, the influence of different fiber contents on the concrete-damage process was analyzed. Results show that MPF can significantly improve the deformability of concrete, and specimens with 1.0 and $2.0 \mathrm{~kg} / \mathrm{m}^{3}$ contents can increase by $35.8 \%$ and $66 \%$, respectively. However, the improvement in compressive strength is not obvious, and the fiber content of $2.0 \mathrm{~kg} / \mathrm{m}^{3}$ can decrease the strength by $7 \%$. AE parameters can effectively reflect the development and degree of damage during concrete loading. With increased polyester fiber, AE activity decreases significantly, and shears failure is effectively suppressed. In the later stage of loading, the proportion of medium and high-frequency signals decrease, and main-frequency distribution moves forward to $70 \%$ of relative stress. This finding indicates that the existence of fiber releases energy ahead of time and improves the ductility of concrete, but the bearing capacity decreases when the content is too high. Overall, this study can serve as a reference for exploring the action mechanism of MPF and the design and optimization of fiber concrete.
\end{abstract}

Keywords: Modified polyester fiber, Uniaxial compression, Acoustic emission, RA-AF distribution characteristics

\section{Introduction}

Concrete is the most extensively used engineering material in the world, but its low tensile strength, poor deformation capacity, and weak energy absorption have caused concrete structures to crack easily and thus lose their performance. Accordingly, since the beginning of the last century [1], researchers have added different types of fiber materials into the concrete matrix to improve the above problems. These materials include steel fiber, polypropylene fiber, carbon fiber, glass fiber, and basalt fiber [2]. Polyester fiber has a low cost and wide-ranging source, but it was used only in asphalt concrete in the past years due to poor alkali resistance [3]. However, with the continuous development of material technology, modified polyester fiber (MPF) has solved the problem of poor alkali resistance [4,5] and has gradually been used in various concrete projects.

However, the properties of fiber-reinforced concrete (FRC) materials differ according to various practical engineering requirements, and unreasonable content and type of fiber lead to decreased concrete properties. Therefore, how to determine the reasonable amount and size of polyester fiber to meet the structural requirements of specific projects is highly important in the application of MPF concrete.

On this basis, numerous experimental studies on the

*E-mail address: gaoyu_ustb@163.com

ISSN: 1791-2377 @ 2021 School of Science, IHU. All rights reserved.

doi:10.25103/jestr.144.22 mechanical properties and durability of concrete with different contents of polyester fiber have been carried out [69]. However, these studies cannot accurately explain the influence of fiber content on the damage process and state of concrete structure under stress conditions. Thus, they cannot determine the influence of polyester fiber on concrete performance. Indeed, how to effectively evaluate the influence of different fiber contents on the mechanical properties of concrete and the process and state of fiber inhibiting damage is a problem that urgently needs to be solved.

In the present study, the uniaxial-compression test of MPF reinforced concrete (MPFRC) with different fiber contents was performed based on acoustic emission (AE) technology. The AE parameters during loading were analyzed to clarify the influence and mechanism of different fiber contents on the concrete-damage process and to serve as a reference for the design and optimization of MPF concrete.

\section{State of the art}

Numerous studies have been conducted on the mechanical properties of FRC and the AE characteristics during loading. Khan [10] carried out different mechanical tests on waste polyester FRC (PFRC) with different contents and found good bending and impact resistance. When the fiber content 
exceeds $4 \%$ of the cement mass, the compressive strength decreases, but the influence of the content on its mechanical properties is unclear. Al-Hadithi [11] studied the performance of self-compacting concrete with different contents of polyester fiber under impact load and showed that a reasonable content of polyester fiber can effectively absorb impact energy and thus improve concrete performance. Kasu [12] established the logarithmic relationship between stress level and fatigue life through bending fatigue test. They found that when the content of polyester fiber is $0.9 \mathrm{~kg} / \mathrm{m}^{3}$, concrete performance is obviously higher than in other contents. The study also established the damage-evolution nonlinear model of concrete based on stiffness degradation under different content. Liu [13] studied the internal-structure change characteristics and damage-evolution mechanism of polyester fiber concrete under freeze-thaw cycle by using nuclear magnetic resonance technology, but they did not study the damage identification of concrete specimens during loading. Gifta [14] established an artificial neural network model with various components of fiber concrete as parameters to predict the mechanical properties of fiber concrete; they then verified the effectiveness of the model through experiments. Mohanmmed [15] studied the influence of fiber parameters of polyester fiber concrete on mechanical properties through mechanical tests. They established fiber index parameters to characterize the influence of polyester fiber on the mechanical properties of concrete. Pimanimas [16] established the stress-strain model of polyester fiber concrete and effectively predicted its limit conditions and control points in the stress-strain path.

On the aspect of AE, Li [17] used AE to study the damage mechanism, evolution process, and damage state of basalt FRC under different load levels. Liu [18] determined that fracture mode and damage stage are closely related to fiber content through the AE characteristics of the bending test of basalt FRC with different contents. Sager [19] studied the differences in AE characteristics of steel FRC with different contents under uniaxial-compression test. They evaluated the damage of steel FRC with different contents by using the $\mathrm{AE} \mathrm{b}$ value of each loading stage. Smedt [20] used CT scanning and AE technology to study the damage characteristics of steel FRC during bending test and revealed the actual effect mode of concrete through AF and RA values. Li [21] studied the influence of steel-fiber type, content, and size on the flexural performance of concrete; they then analyzed its fracture process and fracture mode through AE parameters. Wang [22] studied the mechanical properties and $\mathrm{AE}$ characteristics of polypropylene fiber concrete with different fiber contents. Their results show that the failure process of different fiber contents obviously differs but has little effect on compressive strength. Liu [23] used AE technology to study the energy-dissipation mechanism of high-strength concrete in shaft lining under cyclic loading and unloading conditions. Results show that the existence of fiber makes the energy release slower during loading, thereby inhibiting the rockburst of high-strength concrete. Liu [24] carried out a uniaxial compression AE test on polyvinyl alcohol fiber concrete under thermomechanical coupling and obtained the damage state during loading, proving that polyvinyl alcohol fiber can improve the mechanical properties of concrete.

The above studies primarily focus on the mechanical properties of PFRC, The influence of fiber on mechanical properties and damage by $\mathrm{AE}$ technology is also mostly aimed at steel fiber and polypropylene fiber. Conversely, limited experimental research on PFRC has been conducted. In the present study, $\mathrm{AE}$ tests under uniaxial compression were conducted on MPFRC with different contents of polyester fibers to study the effects of different amounts of polyester fibers on the peak strength and deformation capacity of concrete. Furthermore, the AE ringing count, $r$ value, RA-AF distribution, and AE's main frequency characteristics were used to study the AE characteristics, damage state, and mechanism of action of fiber on concrete during specimen loading.

The reminder of this study is organized as follows. Section 3 describes the sample preparation and test-loading plan. In the fourth section, the mechanical properties and $\mathrm{AE}$ parameters of MPF concrete with different contents are obtained through the test results. The last section summarizes the conclusions.

\section{Methodology}

\subsection{Test Materials}

For these tests, P.O42.5 cement was used. The fine aggregate was river sand with a fineness modulus of 2.4 and good grain gradation. The coarse aggregate was two-grade crushed stone (with 5-16 and 16-31.5 mm stones in 1:1 proportion) with regular grains and minimal silt content. The mineral powder was grade S95, with a specific surface area of $420 \mathrm{~m}^{2} / \mathrm{kg}$. The fly ash was grade II, with $94 \%$ watercontent ratio. The MPF used in the test was more stable than ordinary polyester fiber in difficult environments, thereby solving problems of poor alkali resistance, rapid aging, and hydrophilicity [11]. The relevant properties of the fiber are shown in Table 1.

Table 1. Properties of Modified Polyester Fiber

\begin{tabular}{l|l|l|l|l|l}
\hline Specific Gravity $\left(\mathrm{g} \cdot \mathrm{cm}^{-3}\right)$ & Fineness(D) & Length(mm) & Tensile Strength(MPa) & Elongation(\%) & Elasticity Modulus(GPa) \\
\hline $0.9-1.31$ & $9-13$ & 20 & $300-500$ & 30 & $7-12$ \\
\hline
\end{tabular}

Table 2. Mix Ratios of C30 Concrete $\left(\mathrm{kg} / \mathrm{m}^{3}\right)$

\begin{tabular}{l|l|l|l|l|l|l|l|l|l|l}
\hline No. & Cement & Sand & Stone 1 & Stone 2 & Water & $\begin{array}{l}\text { Mineral } \\
\text { powder }\end{array}$ & Fly ash & Fiber & $\begin{array}{l}\text { High performance } \\
\text { water-reducer }\end{array}$ & $\begin{array}{l}\text { Air entraining } \\
\text { agent }\end{array}$ \\
\hline RC & 210 & 680 & 470 & 470 & 176 & 126 & 84 & 0 & 5.88 \\
MPF-1 & 210 & 680 & 470 & 470 & 176 & 126 & 84 & 1 & 5.88 \\
MPF-2 & 210 & 680 & 470 & 470 & 176 & 126 & 84 & 2 & 5.88 \\
\hline
\end{tabular}

\subsection{Mix Ratio}

C30 reference concrete (RC) with a water-binder ratio of 0.42 was used in the tests. To explore the influence of different polyester fiber contents on concrete properties, based on existing literature $[8,11]$, the contents of 1.0 and $2.0 \mathrm{~kg} / \mathrm{m}^{3}$ MPFRC were used as the research specimens, with mix ratios as shown in Table 2. 


\subsection{Mixing Method}

The following mixing method was adopted during production of the test specimens to ensure uniform dispersal of the fibers throughout the slurry. Sandstone and cementitious materials were initially stirred for $60 \mathrm{~s}$, and then water was added, and the mixture stirred for another 60 s. Finally, fibers were added, and the mixture stirred for another $60 \mathrm{~s}[7,11]$. An optical-microscopy image of the fiber distribution after stirring and molding is shown in Figure. 1. The fiber dispersion in specimen MPF-1 is more uniform than that in specimen MPF-2.

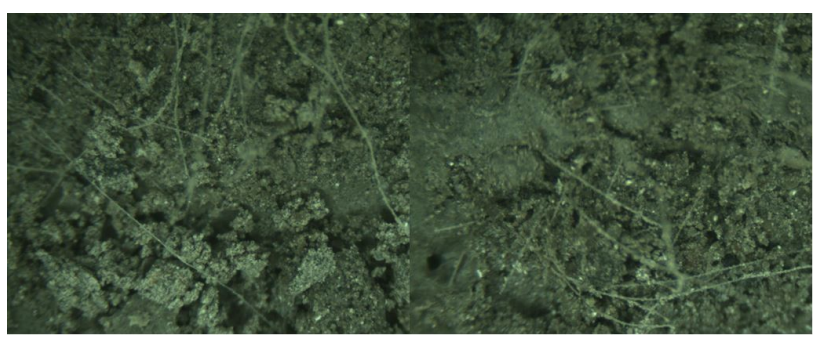

(a)

(b)

Fig. 1. Fiber Dispersion in Concrete. (a) MPF-1. (b) MPF-2

\subsection{Pouring and Curing}

The test specimens were cubes of $100 \mathrm{~mm}$ side length, from which the formwork was removed after 1 day of casting and molding. They were then placed in a curing room for standard curing $\left(20 \pm 2{ }^{\circ} \mathrm{C}, 95 \%\right.$ humidity $)$ for 28 days.

\subsection{Testing Method}

The loading system used a GAW-2000 single-axis electrohydraulic servo rigid-testing machine in load-control mode at a loading rate of $200 \mathrm{~N} / \mathrm{s}$. During the test, the vertical deformation and load data for the concrete specimens were collected using the testing machine's sensors. The AE system was a PCI-2 AE detector. During testing, high and low frequency (resonant frequency $=150$ and $90 \mathrm{kHz}$ ) channels were selected for the collection of AE signals. Table 3 shows the parameter settings used for $\mathrm{AE}$ collection.

Table 3. Parameter Settings for AE Collection

\begin{tabular}{c|c|c|c|c}
\hline $\begin{array}{c}\text { Threshold } \\
(\mathbf{d B})\end{array}$ & $\begin{array}{c}\text { Sampling } \\
\text { Rate } \\
(\text { MSPS) }\end{array}$ & $\begin{array}{c}\text { PDT } \\
(\boldsymbol{\mu s})\end{array}$ & $\begin{array}{c}\text { HDT } \\
(\boldsymbol{\mu s})\end{array}$ & $\begin{array}{c}\text { HLT } \\
(\boldsymbol{\mu s})\end{array}$ \\
\hline 40 & 1 & 40 & 100 & 300 \\
\hline
\end{tabular}

\section{Result Analysis and Discussion}

\subsection{Peak Strength and Deformation}

Uniaxial-compression tests were conducted on the three PFRC groups having different fiber contents with at least three specimens per group. The pre-peak stress-strain curves were obtained, as shown in Figure. 2.

The fiber improved the concrete strength to a certain extent. Compared with RC, the strength of MPF-1 was $8.2 \%$ greater. However, when the fiber content exceeded a certain level, the PFRC strength decreased (the strength of the specimen MPF- 2 was $7.0 \%$ lower than that of RC). The addition of fiber also significantly improved the deformation capacity of concrete. Compared with $\mathrm{RC}$, the strain at peak stress of MPF-1 and MPF-2 were greater by $35.8 \%$ and $66.0 \%$, respectively, as detailed in Table 4.

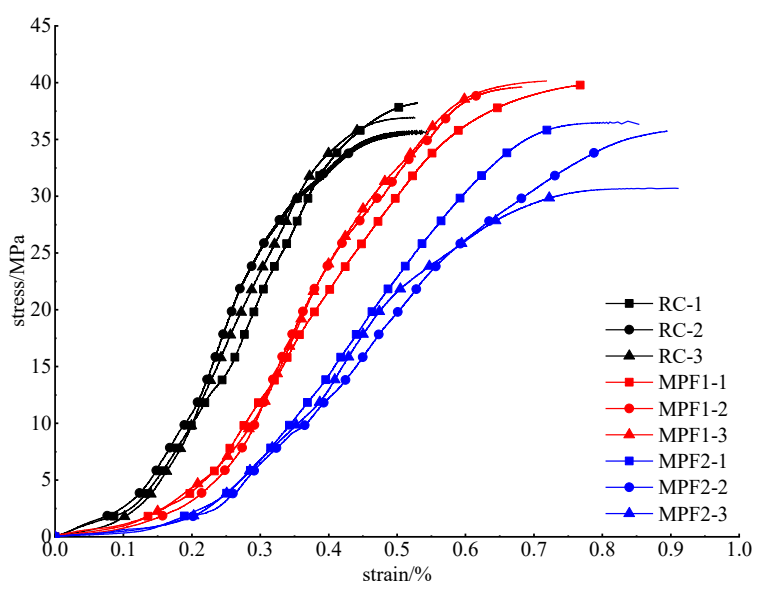

Fig. 2. Pre-peak Stress-Strain Curves under Uniaxial Compression

Table 4. Uniaxial-compression Test Data for Modified PFRC

\begin{tabular}{|c|c|c|c|c|}
\hline No. & $\begin{array}{c}\text { Peak Stress } \\
(\mathrm{MPa})\end{array}$ & $\begin{array}{c}\text { Average } \\
(\mathrm{MPa})\end{array}$ & $\begin{array}{c}\text { Strain at } \\
\text { Peak Stress } \\
(\%)\end{array}$ & $\begin{array}{c}\text { Average } \\
(\%)\end{array}$ \\
\hline \multirow{3}{*}{$\mathrm{RC}$} & 38.16 & \multirow{3}{*}{36.84} & 0.53 & \multirow{3}{*}{0.53} \\
\hline & 35.45 & & 0.54 & \\
\hline & 36.92 & & 0.53 & \\
\hline \multirow{3}{*}{ MPF-1 } & 39.79 & \multirow{3}{*}{39.85} & 0.77 & \multirow{3}{*}{0.72} \\
\hline & 39.62 & & 0.68 & \\
\hline & 40.15 & & 0.72 & \\
\hline \multirow{3}{*}{ MPF-2 } & 36.33 & \multirow{3}{*}{34.25} & 0.85 & \multirow{3}{*}{0.88} \\
\hline & 35.76 & & 0.89 & \\
\hline & 30.67 & & 0.91 & \\
\hline
\end{tabular}

Under uniaxial compression, the failure of cube specimens was caused by vertical cracks, which propagate and interpenetrate when the transverse tensile stress in the specimen exceeded its tensile strength. Due to the good tensile properties and cohesiveness of polyester fiber, after its addition, a spatial network "fiber rebar" structure formed within the concrete matrix, which bore the tensile stress together with the matrix. This phenomenon prevented the occurrence and propagation of cracks, thereby improving the deformation capacity of concrete and clearly lengthening its plastic stage. However, polyester fiber cannot significantly improve the tensile strength of concrete, and with further increased fiber content, the workability of the cement slurry was diminished, resulting in molding defects. The resulting microstructure was not as dense as that of the $\mathrm{RC}$, reducing these specimens' compressive strength by comparison.

\subsection{AE Ringing Parameters}

$\mathrm{AE}$ ringing is the fundamental parameter of $\mathrm{AE}$, indicative of the intensity and frequency of signals and closely related to the number and propagation of cracks occurring during loading [21]. In the present study, the $\mathrm{AE}$ characteristics of PFRC with different fiber contents under uniaxial loading were analyzed based on the ringing count rate and cumulative count curve. The ringing count rate, an AE state parameter, reflected AE changes during different loading stages and was directly related to the deformation rate and crack propagation rate of the specimen. Cumulative ring counts, an AE process parameter, indicated the overall $\mathrm{AE}$ intensity and the cumulative effect of internal damage within the specimen. The data collected before reaching the peak stress were normalized, and AE count rates under relative stress were obtained by summing the ringing counts for each $1 \%$ relative stress interval, as shown in Figure. 3. In the 
figure, LF denotes low-frequency channel count, and HF denotes high-frequency channel count.

Analysis of the AE ringing count rate characteristics for concrete specimens with different fiber contents revealed that the LF ringing count rate was higher than the HF ringing count rate during each stage of concrete loading. This finding reflected the different resonant frequencies of the LF and HF sensors. However, the trends of changes in LF and $\mathrm{HF}$ ringing count rates were very similar, indicating a degree of consistency in the response of the two channels to the damage occurring in the specimen during loading. The changes in ringing count rate went through five stages. We take Figure. 3(a) as an example. (I) in the initial stage of AE, up to about $10 \%$ of peak stress, the primary pores and fractures in the specimen were compacted, and the ringing count rate dropped and stabilized. (II) During the $\mathrm{AE}$ acceleration period, microscopic cracks in the specimen emerged continuously, and the ringing count rate increased rapidly until about $40 \%$ of peak stress. (III) During the $\mathrm{AE}$ stable development stage, after increasing to a certain level during stage II, AE remained relatively steady as microscopic cracks in the specimen began to propagate to form macroscopic cracks. This phenomenon continued until about $80 \%$ of peak stress. (IV) During the AE deceleration stage, the ringing count rate dropped rapidly. The macroscopic cracks that formed in stage III began to propagate and interpenetrate, forming macroscopic fractures; conversely, the specimen began to display signs of local damage, until around $95 \%$ of peak stress. (V) During the AE end stage, the ringing count rate sharply increased after the rapid drop in stage IV. The macroscopic fractures in the specimen interpenetrated to form a failure surface, leading to structural instability and loss of bearing capacity.

Comparison of Figures. 3(a), (b), and (c) revealed significant differences between the ringing count rate curves for RC, MPF-1, and MPF-2. (1) Figures. 3(b) and (c) lack an obvious stage III, indicating that the addition of polyester fiber inhibited the formation of macroscopic cracks. (2) The smoothness of the ringing count rate curves differed: Figures. 3(b) and (c) display marked fluctuations, whereas the curves in Figure. 3(a) were smoother. This finding also indicated that MPF inhibited internal damage within the concrete.

Comparison of Figures. 2 and 3 revealed a reasonable correspondence between the cumulative ringing count and stress-strain curves, suggesting that the cumulative ringing count reflected the damage level of the specimen during loading. The total cumulative ringing counts of concrete with different fiber contents were ranked RC $>$ MPF-1 > MPF-2, indicating that MPF reduced the damage to specimens during loading. Moreover, the ringing counts for all three groups of specimens collected by the LF channel were much larger than those of the HF channel, a ratio that increased linearly from 2.75 times for RC and by to 52.3 times for MPF-2, indicating that MPF greatly reduced the occurrence of HF events.

\subsection{AE r Value}

The AE $r$ value reflects the degree of energy concentration and the specimen's crack propagation state during loading. This value is the ratio of AE impacts to energy, expressed as $r=N(i) / E(i)$, where i represents the relative stress. A large $\mathrm{r}$ value indicates the occurrence of a large number of low energy AE events, often reflecting the formation and propagation of microscopic cracks. A small $r$ value indicates the occurrence of a small number of high energy AE events and often reflects the incubation and interpenetration of macroscopic cracks [22-25].

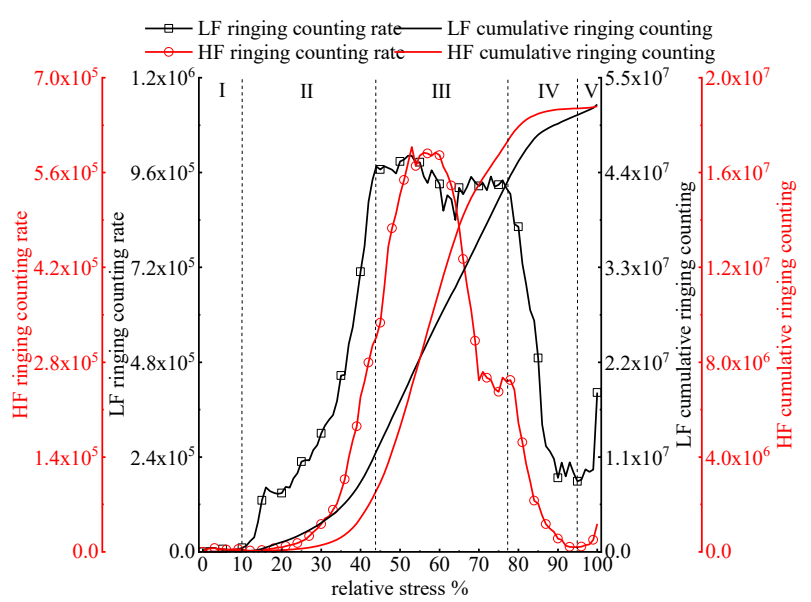

(a)

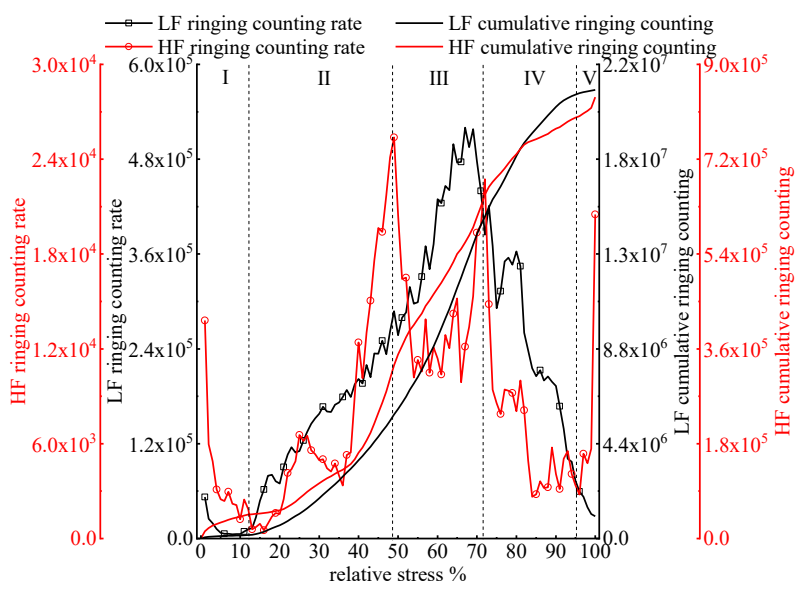

(b)

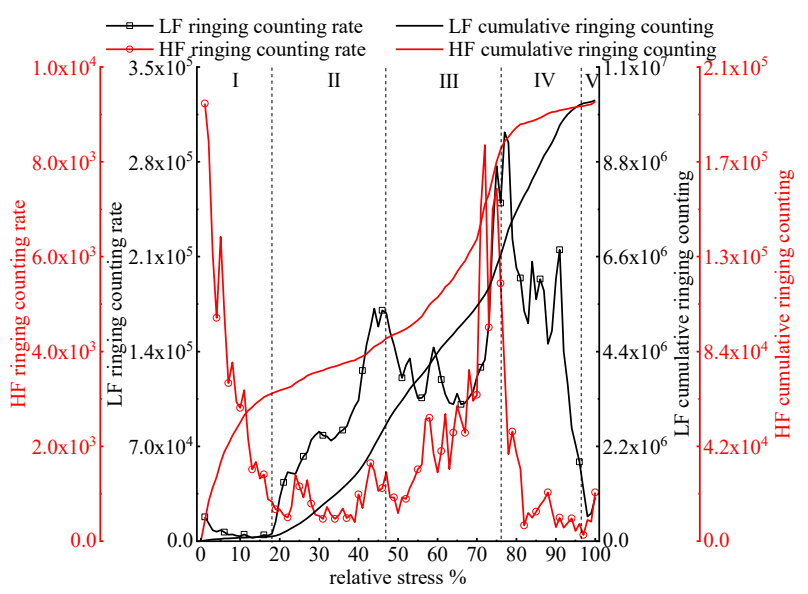

(c)

Fig. 3. FRC Relative Stress-Ringing Count Curves. (a) RC. (b) MPF-1. (c) MPF-2

Figure. 4 presents the AE $\mathrm{r}$ value curves for modified PFRC with different fiber contents under uniaxial compression. LF is the $\mathrm{r}$ value for the low-frequency channel, and HF is the $r$ value for the high-frequency channel. Figure 4 shows that the LF and HF r values increased slowly during the initial stage of loading as internal primary pores and fissures were compacted, resulting in structural damage and energy release. After the compaction stage ended, at about $10 \%$ relative stress, the $\mathrm{r}$ value rapidly increased, reaching a 
peak before beginning to fall, indicating the occurrence of numerous low-energy events, i.e., the emergence of microscopic cracks. At this time, the LF and HF channel AE signals began to differ, with the LF channel $r$ value reaching its peak earlier than the HF channel. This finding indicated that the low-energy LF AE events induced the HF lowenergy AE events. Moreover, the HF channel $r$ value was sustained at a high level for a considerable period, indicating that the AE signals produced by the emergence of microscopic cracks were primarily HF low-energy signals. After the $r$ value decreased, the LF and HF channels remained at a lower level, and the LF $\mathrm{r}$ value approached 0 . These results indicated that during the propagation and interpenetration of macroscopic cracks, primarily LF high energy AE signals occurred, accompanied by some $\mathrm{HF}$ medium energy signals. However, Figures. 4(b) and (c) show that with increased levels of polyester fiber content, the $r$ value was higher at this stage, indicating that the fiber effectively inhibited the high-energy AE events, with HF signals being particularly sensitive. Analysis of the shapes of the curves revealed that the LF and HF $r$ value curves in Figure. 4(a) were relatively smooth. Figure. 4(b) shows that the LF $\mathrm{r}$ value curve was smooth, but HF curve extensively fluctuated. Figure. 4(c) shows that the LF and HF r value curves considerably fluctuated, but the HF $r$ value fluctuated more sharply. This finding also indicated MPF's ability to prevent cracks to some extent. As stress exceeded $80 \%$, the $r$ value began to rise and then rapidly decreased before reaching peak stress. At this stage, the propagation of macroscopic cracks rendered the specimen unstable and severely damaged. The AE LF and HF channels initially indicated a great number of medium-energy events followed by high-energy events before the specimen was destroyed.

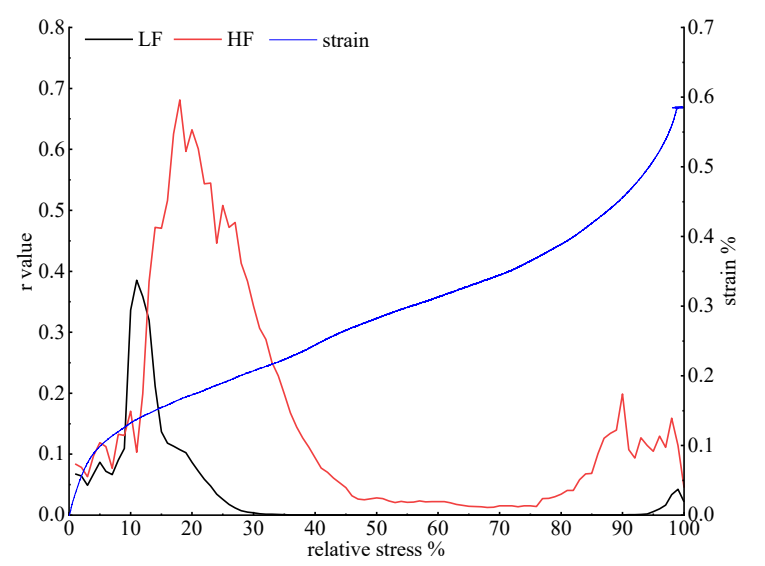

(a)

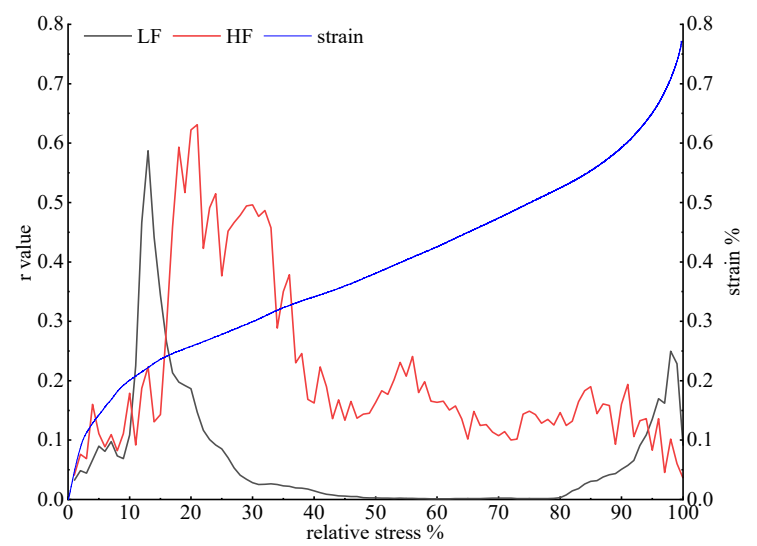

(b)

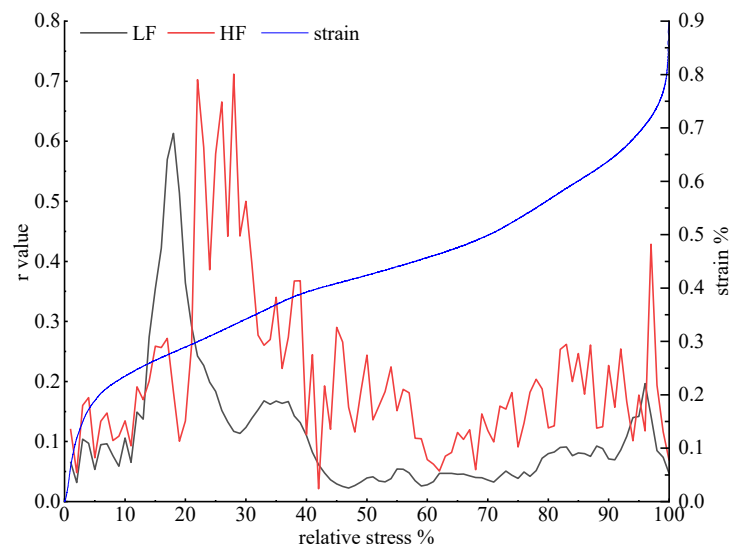

(c)

Fig. 4. Concrete r Value Curves. (a) RC. (b) MPF-1. (c) MPF-2

\subsection{RA-AF Distribution Characteristics}

The damage process of concrete cube specimens under uniaxial compression was due to internal tensile stress and shear stress. The resistance to tensile stress and shear stress was invariably increased by the addition of polyester fiber, as shown in Figure. 5. Figure. 5(a) shows a typical tensile crack. The MPF fibers were elongated and thinned during the process of resisting tensile stress before finally failing. Figure. 5(b) shows a typical shear crack, where the fibers were sheared due to shear stresses.

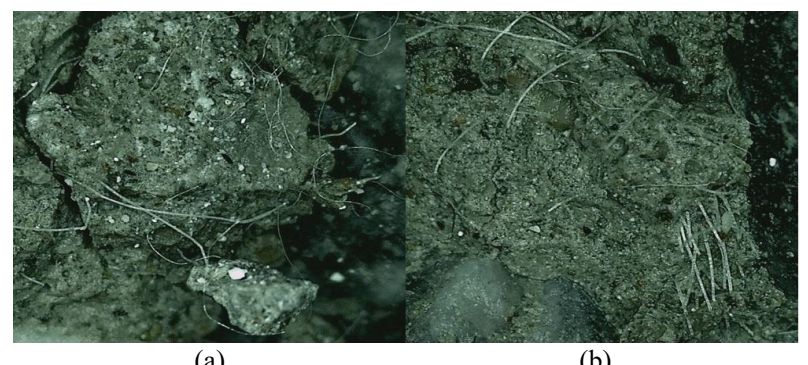

(a)

(b)

Fig. 5. Typical Failure Modes. (a) Tensile Crack. (b) Shear Crack

Apparently, due to its fiber content, the form of internal stresses in FRC was modified, resulting in a fracture mode that clearly differed from that of RC. In this study, the AE characteristic parameter RA value (rise time and amplitude, $\mathrm{ms} / \mathrm{V}$ ) and the average frequency $(\mathrm{AF}, \mathrm{kHz})$ were used to evaluate the cracking mode of the material [26]. In general, for tensile cracks, the corresponding RA value was small, whereas the AF value was large. For shear cracks, the corresponding RA value was large, whereas the AF value was small [27].

The AE RA-AF parameters in the LF and HF channel data from concrete specimens with different fiber contents were analyzed, and results are shown in Figure. 6. The AE events in $\mathrm{RC}$ arising from pure shear cracks were clearly more numerous than those arising from tensile cracking. Thus, the cumulative damage arising in ordinary RC concrete cube specimens during compression was primarily caused by a shearing or tensile shearing action. However, analysis of the AE peak frequency parameters indicated that the proportion of predominantly HF signals greatly increased in the later stages of loading, indicating that the final damage to the specimen was inflicted by tensile cracking. With increased polyester-fiber content, the distribution of RA values progressively narrowed, most notably in Figure. 6(f). This finding showed that the addition of polyester fiber clearly inhibited the internal shear cracking of the specimen. 


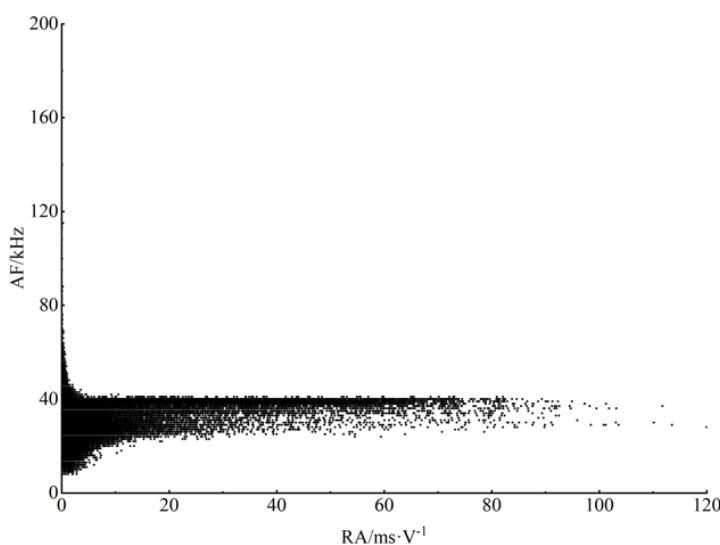

(a)

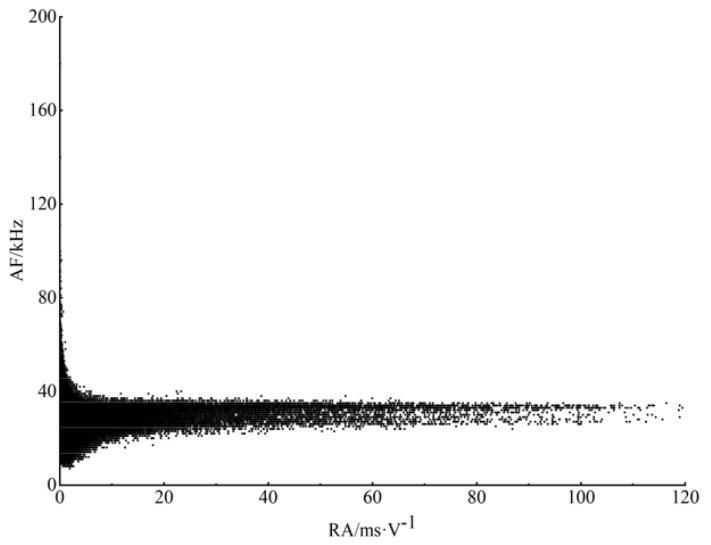

(c)

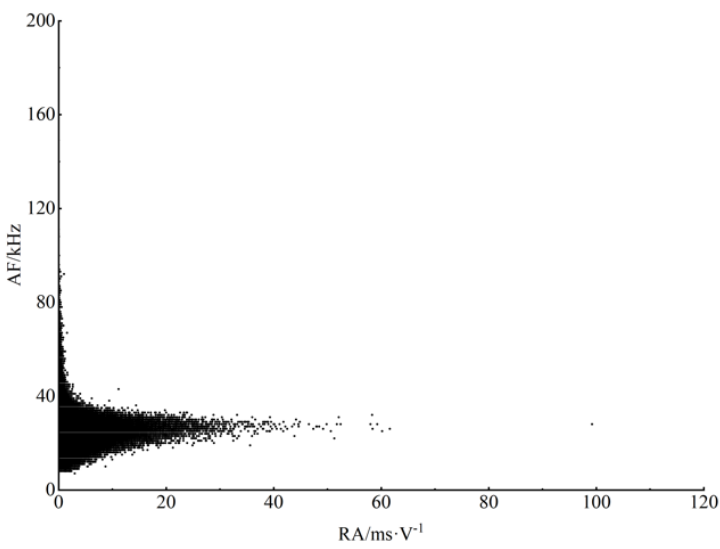

(e)

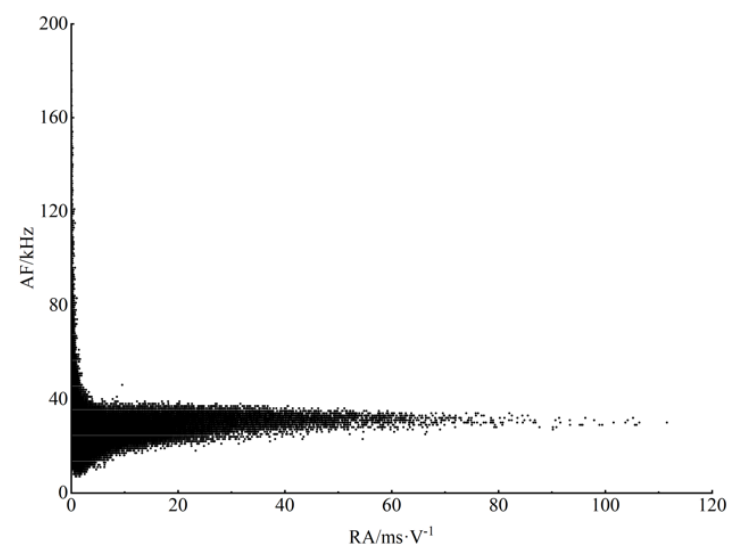

(b)

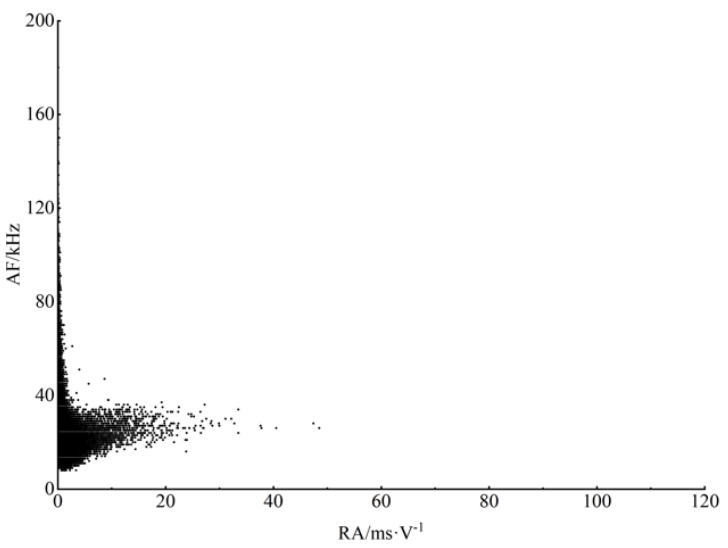

(d)

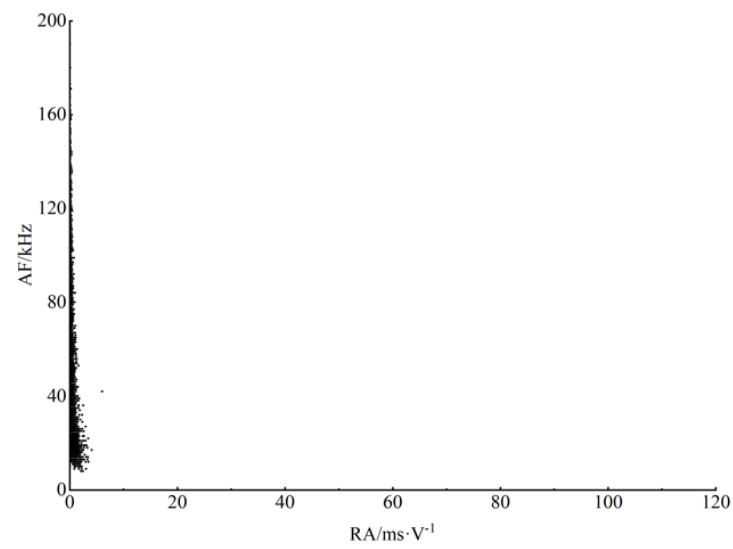

(f)

Fig. 6. RA-AF Distribution of AE in LF and HF Channels for Concrete with Different Fiber Contents. (a) RC LF channel. (b) RC HF channel. (c) MPF-1 LF channel. (d) MPF-1 HF channel. (e) MPF-2 LF channel. (f) MPF-2 HF channel

\subsection{Main-Frequency Characteristics}

AE waveforms' stage characteristics and spectrumdevelopment processes closely reflect the relationship between the loading state of the materials under test, as well as the laws governing the evolution of their internal cracks [28] and their deformation and damage processes. The simple harmonic vibration corresponding to the AE signal's main frequency was close to that of the original irregular acoustic signal; thus, this major frequency was selected as the characteristic index of the AE spectrum.

In this work, the PCI-2 system was used to perform fast Fourier transform on AE signals generated during specimen loading to obtain the main frequency of each waveform signal, as well as to integrate the LF and HF channel signals to form a $35-200 \mathrm{kHz}$ broad-frequency distribution. Based on the main-frequency distribution, signals were mostly in the low $(35-70 \mathrm{kHz})$, intermediate $(85-100 \mathrm{kHz})$, and highfrequency $(130-160 \mathrm{kHz})$ ranges. The proportion of $\mathrm{AE}$ signals in each $1 \%$ relative stress interval in each frequency band was calculated to determine the proportional variation of AE signals across bands for the three groups of specimens under different stress levels. Results are shown in Figure 7.

Figure. 7 indicates that all three frequency bands display a general trend of "rising, falling, and then rising." The difference was that the low-frequency band data began to rise after $10 \%$ relative stress, and its proportion of $\mathrm{AE}$ signals during loading remained relatively stable, varying between $0 \%$ and $2.5 \%$. The AE signals within the $85-100$ and $130-160 \mathrm{kHz}$ frequency ranges accounted for a larger proportion in the initial $(0 \%-15 \%)$ and late $(70 \%-100 \%)$ stages of loading, especially the latter. By contrast, during 
the intermediate stage, these bands' proportion of AE signals was very small. This finding showed that while lowfrequency AE signals occurred more or less throughout concrete loading, intermediate and high-frequency $\mathrm{AE}$ signals were much more prevalent and close to the peak stress. This characteristic could serve as a warning of concrete damage.

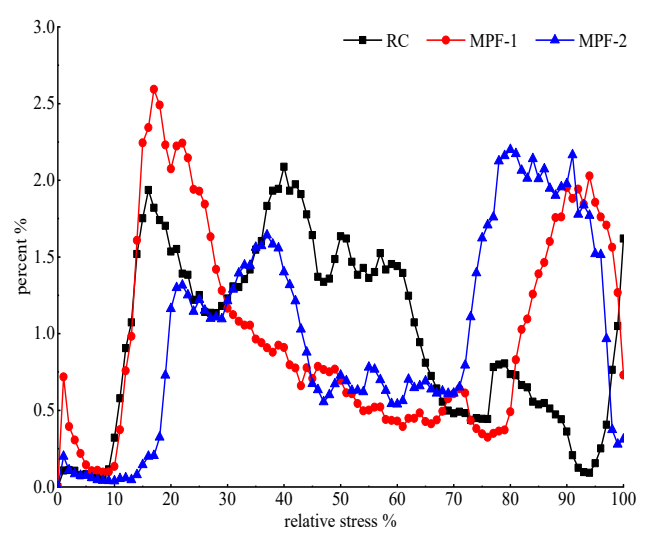

(a)

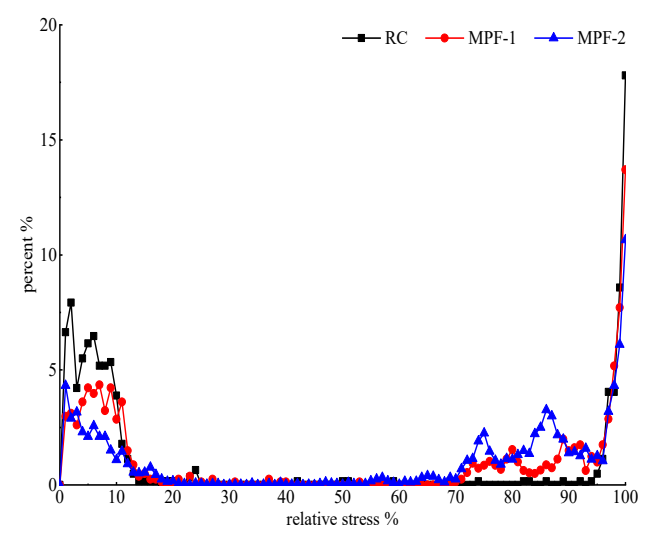

(b)

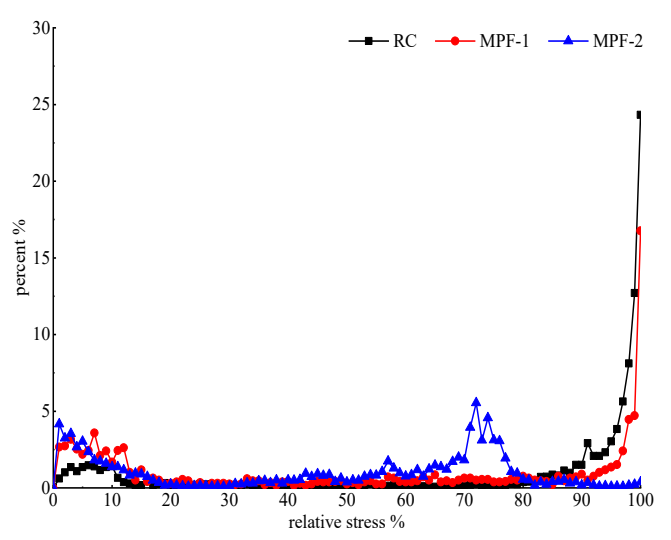

(c)

Fig. 7. Proportional Variation Curves of AE Signals in Different Frequency Bands. (a) $35-70 \mathrm{kHz}$. (b) $85-100 \mathrm{kHz}$. (c) $130-160 \mathrm{kHz}$

The impact of MPF on the main-frequency distribution of $\mathrm{AE}$ was primarily reflected in the shift of the mainfrequency distribution into the later stage of loading (over $70 \%$ of the relative stress) and the decrease in the proportion of the signal during critical damage. As shown in Figure. 7(a), for $\mathrm{RC}$, the proportion of AE signals rapidly increased at about $90 \%$ of relative stress, whereas that of MPF- 1 and MPF-2 rapidly increased after $80 \%$ and $70 \%$, respectively, dropping after $90 \%$. Figure. 7 (b) shows that for RC, the proportion of AE signals rapidly increased at about $95 \%$ of relative stress, whereas that of MPF-1 and MPF-2 slowly increased after $70 \%$, and then rises rapidly at about $95 \%$. Figure. 7(c) shows that for RC and MPF-1, the proportion of AE signals rapidly increased at about $90 \%$ of relative stress, whereas that of MPF-2 initially increased at around $70 \%$ and then decreased.

The addition of MPF can significantly inhibit the propagation of cracks of different sizes, particularly in latestage loading. Furthermore, the advancement of the mainfrequency distribution indicated that the damage to FRC specimen was brought forward. This phenomenon, together with the increase in energy release, prevented brittle failure and improved the concrete ductility. Meanwhile, due to the damage brought forward, the capacity of the concrete structure to resist higher stress was reduced, which is one of the reasons why MPF cannot significantly enhance the compressive strength of concrete.

\section{Conclusions}

To effectively evaluate the influence of different fiber contents on the mechanical properties of concrete, the process and state of fiber inhibiting damage, and the optimization of MPF concrete material, this study analyzed the AE characteristics of three groups of specimens during loading through uniaxial compression $\mathrm{AE}$ test. The following conclusions could be drawn:

(1) MPF significantly improves the deformation capacity and ductility of concrete. In terms of compressive strength, with increased fiber content, compressive strength increases until it reaches a peak, thereafter declining with further increased fiber content. The findings indicate that the optimum content of polyester fiber was $1.0 \mathrm{~kg} / \mathrm{m}^{3}$.

(2) The loading process can be divided into five stages based on changes in the AE relative ringing count rate. Fiber addition markedly reduces AE activity in stage III (the stable development stage). Further taking into consideration the $r$ value analysis, polyester fiber is found to reduce the number of high-energy events, indicating that it plays a role in inhibiting crack propagation during concrete loading.

(3) The AE RA-AF distribution state reveal that RC specimens' AE events are primarily caused by shear and tension-shear activity. With fiber addition, the shearing damage is clearly inhibited, and more damage is caused by tensile stress. This phenomenon also explains why the MPF cannot significantly enhance the compressive strength of the concrete. Considering all factors, the optimum fiber content is determined to be $1.0 \mathrm{~kg} / \mathrm{m}^{3}$.

(4) The main $\mathrm{AE}$ frequencies during concrete loading occur in three characteristic frequency bands, namely, 35-70, 85-100, and 130-160 kHz. With increased fiber content, during late-stage loading, the proportions of intermediate and high-frequency signals decrease. Furthermore, the addition of fiber shifts the main-frequency distributions of all frequency bands into the late stage of loading, indicating that the bringing forward of damage reduces the capacity of the specimen to resist external forces.

Additionally, AE technology was used to determine the influence of MPF on the damage process of concrete. The optimum content of fiber for this study was put forward, which provided a certain reference for research on the damage mechanism and engineering application of MPF concrete. Herein, only uniaxial compression was analyzed. 
In future work, related tests on different mechanical properties of MPFRC will be carried out to further elucidate the engineering performance of MPFRC.

\section{Acknowledgements}

This work was supported by the State Key Research Development Program of China (Grant No.
2016YFC0600801) and the National Natural Science Foundation of China (Grant No. 51774021).

This is an Open Access article distributed under the terms of the Creative Commons Attribution License.

\section{References}

1. Rouhollah, R., Mohammand, Z., Mansoor, M., Davoo, M., Sayyed, M. A., "A review on performance of polyester fibers in alkaline and cementitious composites environments". Construction and Building Materials, 241, 2020, pp.117998.

2. Andrzej, M. B., "Fibre reinforced cement-based (FRC) composites after over 40 years of development in building and civil engineering". Composite Structures, 86(1-3), 2008, pp. 3-9.

3. Wu, J. R., Li, F., Ma, Q. Y., "Effect of polyester fiber on air voids and low-temperature crack resistance of permeable asphalt mixture". Advances in Civil Engineering, 5, 2020, pp. 2381504.

4. Mi, S. H., Yaewon, P., Chung, H. P., "Development of superhydrophobic polyester fabrics using alkaline hydrolysis and coating with fluorinated polymers". Fibers and Polymers, 17(2), 2016, pp. 241-247.

5. Saroj, G., Kanta, R., Jayabrata, S., "Evaluation of polyester fiber reinforced concrete for use in cement concrete pavement works". Road Materials and Pavement Design, 9(3), 2008, pp. 441-461.

6. Zhou, M. K., Fang, D., Jiang, D. Y., Liu, W., "Research on the fracture properties and modification mechanism of polyester fiber and SBR latex modified cement concrete". Advances in Materials Science and Engineering, 2016, doi: org/10.1155/2016/5163702.

7. Venu, M., Neelakanteswara, R. P., "Polyester fibers in the concrete an experimental investigation". Advanced Materials Research, 261263, 2011, pp. 125-129.

8. Srikanth, K., D. Ravi, P., "Influence of hybrid fibres on strength and stress-strain behaviour of concrete under uni-axial stresses". Construction and Building Materials, 207, 2019, pp. 238-248.

9. Chen, J. Q., Ji, H. G., Liu, J. H., Yang, F., "Dispersivity of modified polyester fibers in concrete and its influence on the durability of concrete". Chinese Journal of Engineering, 38(11), 2016, pp. 16031609.

10. Muhanmmad, I. K., Muhanmmad, U., Khubab, S., Abdul B., Yasir, N., Muhanmmad, K. "Impact of waste fibers on the mechanical performance of concrete composites". Journal of the Textile Institute, 111(11), 2020, pp. 1632-1640.

11. Abdulkader, I. A., Ahmed, T. N., Waseem, K. M., "Mechanical properties and impact behavior of PET fiber reinforced selfcompacting concrete (SCC)". Composite Structures, 224, 2019, pp. 111021.

12. Sridhar, R. K., Nilanjan, M., Amarnatha, R. M., "Influence of polyester microfiber reinforcement on flexural fatigue characteristics of concrete". Road Materials and Pavement Design, 2020, doi: 10.1080/14680629.2020.1808521.

13. Liu, T. Y., Zhang, C. Y., Zhou, K. P., Tian, Y. G., "Freeze-thaw cycling damage evolution of additivecement mortar". European Journal of Environmental and Civil Engineering, 2019, doi: 10.1080/19648189. 2019.1615992.

14. Christopher, C. C., Ramesh, G., "Modelling of strength and energy absorption capacity of hybrid fibre-reinforced concrete". Magazine of Concrete Research, 73(8), 2021, pp. 410-419.

15. Azad, A. M., Ilham, I. M., "Effect of Fiber Parameters on the Strength Properties of Concrete Reinforced with PET Waste Fibers". Iranian Journal of Science and Technology, Transactions of Civil Engineering, 45, 2021, pp. 1493-1509.
16. Amorn, P., Shahzad S., "Evaluation of Existing Stress-Strain Models and Modeling of PET FRP-Confined Concrete". Journal of Materials in Civil Engineering, 31(12), 2019, pp.04019303.

17. Li, G. D., Zhang, L., Zhao, F. N., Tang, J. Q., "Acoustic Emission Characteristics and Damage Mechanisms Investigation of Basalt Fiber Concrete with Recycled Aggregate". Materials, 13(18), 2020, pp. 4009.

18. Liu, H. B., Liu, S. Q., Zhou, P. L., Zhang, Y. W., Jiao, Y. B., "Mechanical Properties and Crack Classification of Basalt Fiber RPC Based on Acoustic Emission Parameters". Applied Sciences, 9(18), 2019, pp. 3931.

19. R. Vidya, S., Swarnangshu, G., Preeti, J. K., Mohit, S., "Influence of fiber content on acoustic emission characteristics related to steel fiber-reinforced concrete subjected to unconfined uniaxial compression". Journal of Materials in Civil Engineering, 33(5), 2021, pp. 04021073.

20. Maure, D. S., Rutger, V., Charlotte, V. S., Els, V., Lucie, V., "Damage analysis in steel fiber reinforced concrete under monotonic and cyclic bending by means of acoustic emission monitoring". Cement and Concrete Composites, 114, 2020, pp. 103765 .

21. Li, B., Xu, L. H., Shi, Y. C., Chi, Y., Liu, Q., Li, C. N., "Effects of fiber type, volume fraction and aspect ratio on the flexural and acoustic emission behaviors of steel fiber reinforced concrete". Construction and Building Materials, 181, 2018, pp. 474-486.

22. Wang, Y., Chen, S. J., Xu, Z. Z., Liu, S. J., Hu, H. X., "Damage Processes of Polypropylene Fiber Reinforced Mortar in Different Fiber Content Revealed by Acoustic Emission Behavior". Journal of Wuhan University of Technology (Materials Science), 33(1), 2018, pp. 155-163.

23. Liu, J. H., Zhou, Y. C., Ji, H. G., "Energy evolution mechanism of shaft wall concrete under uniaxial loading and unloading compression". Journal of China Coal Society, 43(12), 2018, pp. 3354-3370.

24. Liu, X., Yang, D. Y., Liu, L., Lyu, J. F., "Mechanical Properties and Acoustic Emission Response of PVA Fiber Reinforced Concrete Under Thermo-mechanical Coupling”. Materials Reports, 32(18), 2018, pp. 3135-3141.

25. Zhao, Y., Liu, B., "Deformation Field and Acoustic Emission Characteristics of Weakly Cemented Rock under Brazilian Splitting Test”. Natural Resources Research, 30(2), 2021, pp. 1925-1939.

26. Aggelis, D.G., Mpalaskas, A.C., Matikas, T.E., “Acoustic signature of different fracture modes in marble and cementitious materials under flexural load". Mechanics Research Communications, 47, 2013, pp. 39-43.

27. Gan. Y. X., Wu, S. C., Ren, Y., Zhang, G., "Evaluation indexes of granite splitting failure based on RA and AF of AE parameters". Rock and Soil Mechanics, 41(7), 2020, pp. 2324-2332.

28. Liu, X., Liu, Z., Li, X., Han, M., Yang, L., “Acoustic emission and micro-rupture characteristics of rocks under Brazilian splitting load". Chinese Journal of Engineering, 41(11), 2019, pp. 14221432 . 